\title{
ANALISIS POTENSI DESA WISATA PULESARI MENUJU DESA WISATA HALAL TAHUN 2020
}

\author{
Tareq Azis Yanma \\ Ilmu Pemerintahan, Universitas Muhammadiyah Yogyakarta \\ Email: tareqazis76@gmail.com \\ Muchammad Zaenuri \\ Ilmu Pemerintahan, Universitas Muhammadiyah Yogyakarta \\ Email: zaenuri@umy.ac.id
}

\begin{abstract}
Halal tourism village is an innovation in developing tourist village by prioritizing services for Muslim tourists. Halal tourism in Indonesia has only been developed in several regions, such as West Nusa Tenggara, Riau Islands, Aceh and West Sumatra. Pulesari tourism village is a tourism village in Sleman Regency which has halal tourism potential. Attractions that are shown mostly religious nuances. This study aims to analyze and identify the potential of Pulesari Tourism Village that can support the creation of a halal tourism village. This research is a descriptive qualitative research with a field to get data, make observations, documentations and interviews directly. Data analysis in this study combines the theory of tourism potential with several indicators from the Ministry of Tourism regarding halal tourism. The results of this study stated that Pulesari Tourism Village was not ready to be developed into a halal tourism village because several supporting facilities in the service of Muslim tourists had not yet been fulfilled.
\end{abstract}

Keywords: Halal tourism village, Muslim tourists, Pulesari tourism village

\section{Pendahuluan}

Indonesia ialah negara yang di anugerahi kekayaan alam dan seni budaya yang beragam dari Tuhan. Potensi yang dimiliki tersebut tidak ternilai harganya dan modal yang besar bagi Bangsa Indonesia untuk mensejahterakan masyarakatnya. Kekayaan alam dan budaya tersebut dapat di tampilkan dan di kemas menjadi sebuah obyek wisata. Pemerintah melalui Peraturan Mentri Kebudayaan dan Pariwisata telah merencanakan dan mengembangkan lokasi pariwisata sebagai kegiatan industri. 
Menurut Sedarmayanti, dkk (2018: 29) yang dimaksud dengan industri pariwisata adalah "serangkaian sebuah perusahaan dengan beraneka ragam skala, fungsi, lokasi dan bentuk yang mempunyai kaitan fungsional dengan tujuan untuk menghasilkan barang dan jasa yang dibutuhkan oleh wisatawan".

Peraturan Mentri Kebudayaan dan Pariwisata Nomor PM.29/UM.001/MKP/2010 merupakan tahap awal pemerintah dalam mengelola lokasi wisata. Berdasarkan peraturan tersebut fokus utamanya yaitu pada pemberdayaan masyarakat desa melalui pengembangan potensi wisata. Salah satu pemberdayaan masyarakat yaitu dengan membangun dan mengembangkan desa wisata. Desa wisata adalah sebuah wisata yang menampilkan suasana ciri khas desa untuk sekelompok wisatawan yang datang dengan tujuan melihat dan menikmati potensi- potensi yang ada menurut Marsono (2009: 2).

Pembangunan desa wisata tidak bisa lepas dari kearifan lokal dan potensi sumber daya yang ada di desa tersebut (Rahmasari dan Pudjowati 2017). Dengan mengangkat potensi di setiap daerah maka desa wisata akan menarik wisatawan dan mempunyai ciri khas. Data dari Badan Pusat Statistik (BPS) melalui merdeka.com bahwa pada tahun 2018 jumlah desa wisata di Indonesia berjumlah 1.734 desa wisata.

Pengembangan potensi baru yang di sajikan dalam desa wisata adalah inovasi tentang desa wisata halal. Kementrian Pariwisata melalui Tim Percepatan dan Pengembangan Pariwisata Halal sudah mengidentifikasi 10 provinsi yang akan mengembangkan wisata halal tersebut, yaitu Yogyakarta, Jawa Tengah, Jawa Timur, Jawa Barat, Aceh, Riau dan Kepulauan Riau, Jakarta, Sulawesi Selatan, Sumatera Barat, dan Nusa Tenggara Barat. Jumlah desa wisata halal yang di kembangkan sebagai pilot project di Indonesia baru terdapat di 4 provinsi yaitu Provinsi Nusa Tenggara Barat, Provinsi Kepulauan Riau, Provinsi Nangroe Aceh Darusalam, dan Provinsi Sumatra Barat (Destiana dan Astuti 2019). Desa wisata halal terbaik di kutip dari gatra.com berada di Lombok, Nusa Tenggara Timur yang meraih juara pertama yang dinobatkan oleh Indonesia Muslim Travel Index atau IMTI tahun 2019. 
Pembangunan desa wisata tersebut juga ada di Kabupaten Sleman Provinsi Daerah Istimewa Yogyakarta dengan tujuan menarik minat kunjungan wisatawan. Jumlah desa wisata secara keseluruhan saat ini berjumlah sekitar 65 desa wisata yang ada di Kabupaten Sleman menurut data dari Laporan Hasil Klasifikasi Desa Wisata Kabupaten Sleman tahun 2018. Menurut laporan klasifikasi desa wisata tahun 2018 tersebut menyatakan bahwa jumlah desa wisata mengalami pertumbuhan yang sangat pesat. Dari tahun 2016 sampai tahun 2018 peningkatan jumlah desa wisata hampir 2 (dua) kali lipat. Tahun 2016 dengan jumlah 39 desa wisata menjadi 65 desa wisata. Secara umum jumlah wisatawan yang datang ke Sleman terus meningkat dari tahun 2014 sampai tahun 2018.

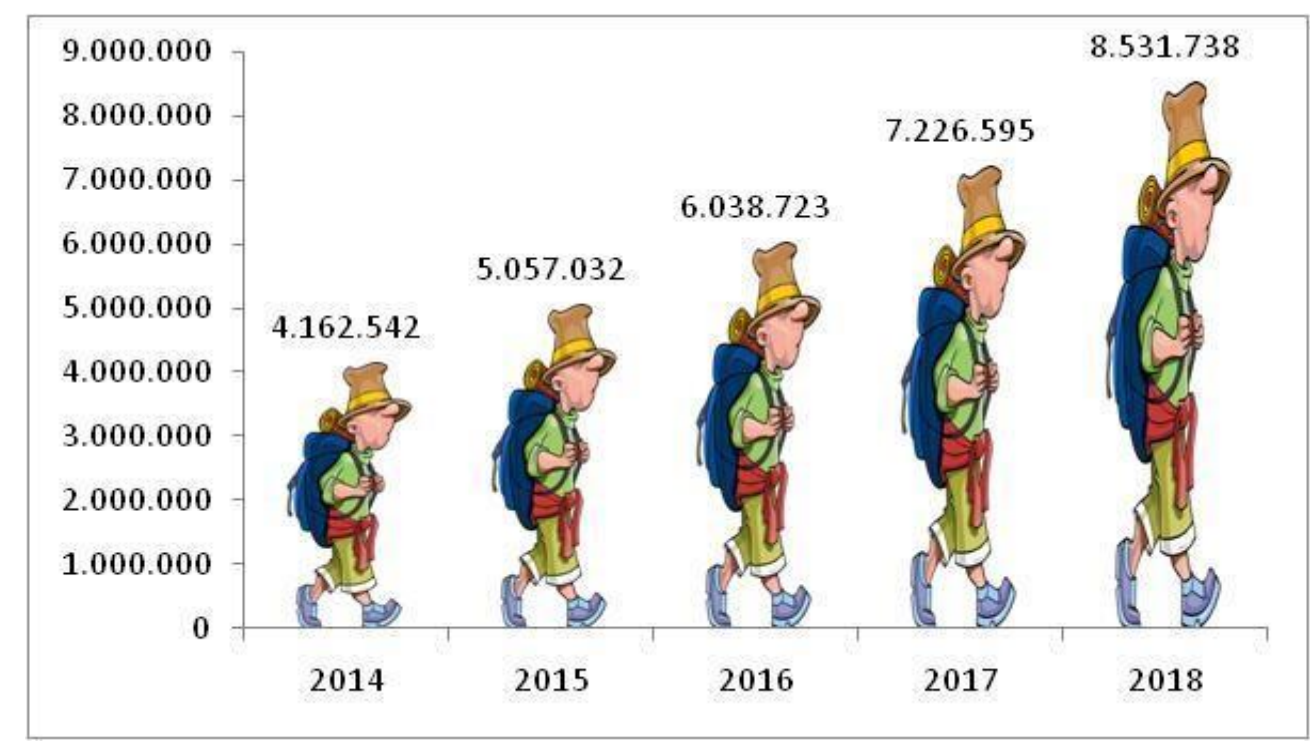

Gambar 1. Jumlah Kunjungan Wisatawan Kabupaten Sleman Tahun 2014-2018 Sumber: https://pariwisata.slemankab.go.id

Pada tahun 2019 Pemerintah Kabupaten Sleman sedang menyongsong wajib halal dikutip dari harianjogja.com. Pemerintah Kabupaten Sleman mewajibkan seluruh pelaku industri dan UMKM memiliki sertifikat halal, termasuk UMKM yang ada di dalam desa wisata dikutip dari tribunjogja.com. Salah satu desa wisata yang mempunyai potensi wisata halal yaitu desa wisata Pulesari. UMKM yang berada di desa wisata Pulesari mempunyai produk olahan dari buah salak yang menjadi 
produk khas. Pada tahun 2019 pengembangan desa wisata halal di Pulesari dengan melibatkan mahasiswa KKN dari Universitas Islam Negeri Sunan Kalijaga Yogyakarta. Pengembangan wisata halal perlu dilakukan karena prestasi Indonesia pada tahun 2019 yang menempatkan diri pada posisi pertama pada Global Halal Tourism tahun 2019, selayaknya pembangunan desa wisata halal segera dilakukan termasuk di Daerah Istimewa Yogyakarta yang masuk dalam wilayah identifikasi 10 Provinsi dalam membangun wisata halal. Berdasarkan beberapa data di atas terkait dengan pembangunan wisata halal, penulis tertarik untuk mengembangkan tulisan tentang sebuah potensi di desa wisata Pulesari yang dapat mendukung dalam pembangunan wisata halal.

\section{Teori}

Wisata halal dalam literatur umum mempunyai persamaan dengan beberapa istilah lainya menurut Putra dalam (Bagus and Irany 2017) seperti, islamic tourism, syari; ah tourism, halal friendly tourism destinatio, muslim friendly tourism destination, dan halal lifestyle. Secara umum pengertian wisata halal adalah sebuah obyek wisata yang mempunyai pelayanan dan fasilitas yang memenuhi ketentuan- ketentuan syariah Islam. Di Indonesia saat ini belum ada peraturan secara nasional tentang pengembangan wisata halal, sehingga menggunakan kriteria- kriteria dari Global Muslim Travel Index sebagai pedoman dalam membangun wisata halal (Subarkah 2018).

Kementrian Pariwisata membentuk sebuh tim yang bertujuan untuk membantu dalam menggambarkan, membangun, dan merumuskan landasan bagi suatu daerah di Indonesia yang akan membangun wisata halal. Tim tersebut bernaman Tim Percepatan Pembangunan Pariwisata Halal atau (TP3H). Terdapat 3 (tiga) kriteria yang disusun oleh TP3H untuk mengembangkan wisata halal (Subarkah 2018), yaitu sebagai berikut: 
Tabel 1. Kriteria Wisata Halal Menurut Kementerian Pariwisata

\begin{tabular}{|c|c|c|}
\hline No & Kategori & Indikator \\
\hline \multirow[t]{5}{*}{1} & \multirow[t]{5}{*}{ Destinasi Pariwisata } & $\begin{array}{l}\text { Aktifitas wisata tidak mengandung unsur } \\
\text { pornoaksi dan kemusrikan. }\end{array}$ \\
\hline & & $\begin{array}{l}\text { Sebisa mungkin menyelengarakan festival } \\
\text { halal life style. }\end{array}$ \\
\hline & & $\begin{array}{l}\text { Pramuwisata mengenakan pakaian dengan } \\
\text { sopan. }\end{array}$ \\
\hline & & $\begin{array}{l}\text { Terdapat pilihan wisata pantai atau } \\
\text { pemandian yang memisahkan antara pria } \\
\text { dan wanita. }\end{array}$ \\
\hline & & $\begin{array}{llr}\text { mempunyai } & \text { peraturan } & \text { larangan } \\
\text { menggunakan } & \text { pakaian minim bagi } \\
\text { pengunjung. } & & \end{array}$ \\
\hline \multirow[t]{4}{*}{2} & \multirow[t]{4}{*}{ Hotel } & Terdapat makanan halal. \\
\hline & & Terdapat fasilitas ibadah (Masjid/ Mushola) \\
\hline & & Terdapat pelayanan saat bulan Ramadhan. \\
\hline & & $\begin{array}{l}\text { Terdapat fasilitas kebugaran yang terpisah } \\
\text { antara pria dan wanita. }\end{array}$ \\
\hline \multirow[t]{4}{*}{3} & \multirow[t]{4}{*}{ Biro Perjalanan } & $\begin{array}{l}\text { Mempunyai paket lokasi wisata yang } \\
\text { memenuhi syarat wisata halal. }\end{array}$ \\
\hline & & $\begin{array}{l}\text { dilarang menawarkan aktifitas/ kegiatan } \\
\text { non- halal. }\end{array}$ \\
\hline & & $\begin{array}{l}\text { Mempunyai daftar tempat penyedia } \\
\text { makanan dan minuman yang bersertifikasi } \\
\text { halal. }\end{array}$ \\
\hline & & $\begin{array}{l}\text { Pemandu wisata sesuai dengan syariah dan } \\
\text { nilai- nilai dalam Islam. }\end{array}$ \\
\hline
\end{tabular}

Kemudian Beberapa kajian potensi tentang objek wisata menurut Yoeti (2006 dalam Wardani and Wesnawa 2018) terdapat beberapa potensi yaitu: 
Tabel 1. Variabel Potensi Objek Wisata

\begin{tabular}{|c|c|c|}
\hline No & Variabel & Indikator \\
\hline \multirow[t]{3}{*}{1} & \multirow[t]{3}{*}{ Potensi Objek Wisata } & Mempunyai daya tarik wisata. \\
\hline & & Mempunyai atraksi wisata. \\
\hline & & Sapta pesona \\
\hline \multirow[t]{3}{*}{2} & \multirow[t]{3}{*}{ Aksesibilitas } & Jaringan transportasi \\
\hline & & Kondisi jalan \\
\hline & & Lokasi objek wisata \\
\hline \multirow[t]{6}{*}{3} & \multirow[t]{6}{*}{ Saran dan prasarana } & Fasilitas akomodasi \\
\hline & & Rumah makan \\
\hline & & Sumber air bersih \\
\hline & & Fasilitas kebersihan \\
\hline & & Fasilitas informasi \\
\hline & & Pengelolaan objek wisata \\
\hline
\end{tabular}

Dalam penelitian ini menggabungkan antara teori potensi obyek wisata dengan beberapa indikator yang sudah di tetapkan oleh Kementrian Pariwisata. Pemilihan alat analisis tersebut karena belum adanya teori secara langsung dalam mengukur potensi wisata halal. Terdapat beberapa modifikasi dalam penggunaan kedua teori untuk menyesuaikan kondisi di lapangan.

\section{Metode Penelitian}

Jenis penelitian yang di gunakan adalah kualitatif yang bersifat deskriptif. Menurut Sugiyono dalam (Jejen 2015) pengertian penelitian kualitatif adalah penelitian yang berisi data bentuk kata, kalimat skema, dan gambar. Objek penelitian ini yaitu di desa wisata Pulesari dan Dinas Pariwisata Kabuapten Sleman. Jenis data yang di butuhkan yaitu data primer dan data sekunder, data primer akan di peroleh melalui wawancara oleh pengurus di desa wisata Dusun Pulesari, dan Dinas 
Pariwisata Kabupaten Sleman. Sedangkan data sekunder yang di butuhkan seperti dokumen pengurus Pokdariw, pengurus desa wisata, dokumen klasifikasi desa wisata, dokumen jumlah wisatawan, dan dokumen tambahan lainya.

\section{Hasil dan Pembahasan}

\section{Potensi Obyek Wisata}

Potensi menjadi unsur paling penting dalam membangun desa wisata, terdapat 7 (tujuh) syarat utama yang di tentukan oleh Dinas Pariwisata Kabupaten Sleman untuk membangun desa wisata yaitu, terdapat susunan kepengurusan, jumlah minimal wisatawan 3 (tiga) kali dalam satu minggu, terdapat atraksi yang di tampilkan, mempunyai makanan dijual, mempunyai souvenir, ruang pertemuan, dan tempat parkir. Keseluruhan syarat tersebut sudah terpenuhi di desa wisata Pulesari, termasuk jumlah wisatawan yang berkunjung cukup tinggi setiap tahunya.

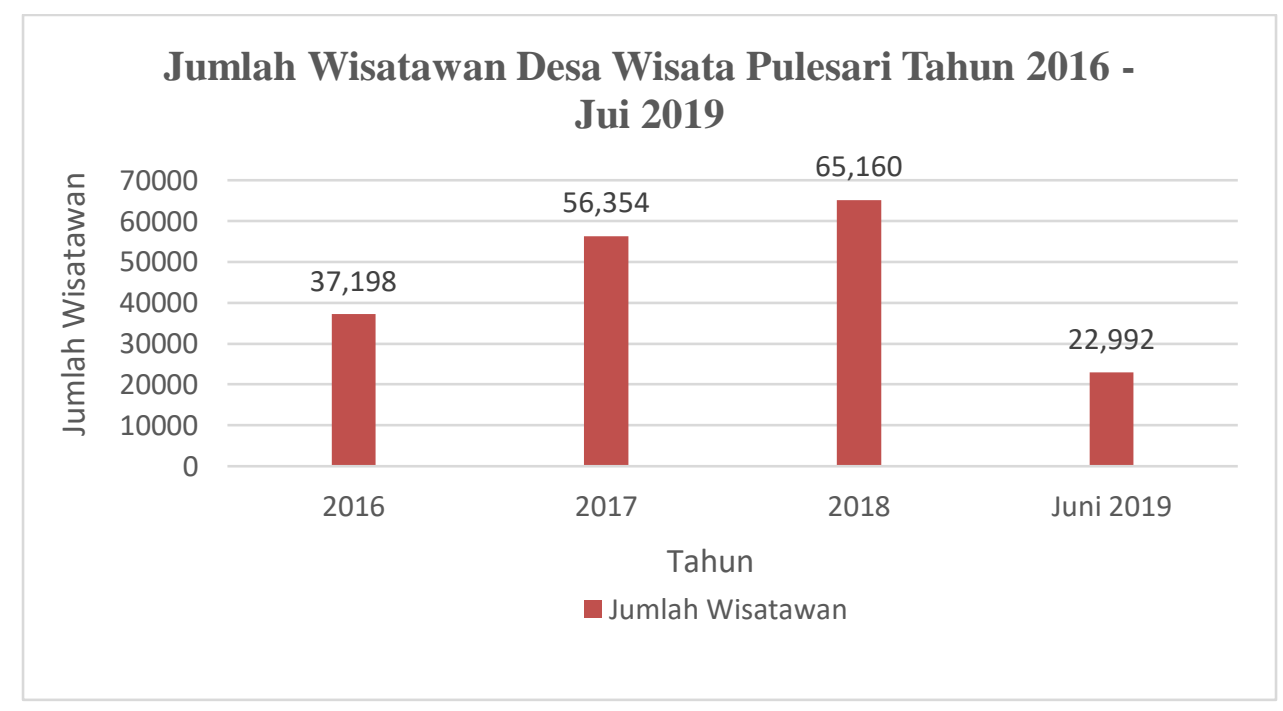

Gambar 2. Jumlah Kunjungan Wisatawan Di Desa Wisata Pulesari

Sumber: Dokumentasi peneliti

Jumlah kunjungan wisatawan di desa wisata Pulesari dari tahun 2016 sampai tahun 2018 mengalami kenaikan, sedangkan pada tahun 2019 jumah kunjungan baru tercatat sampai bulan Juni. Kenaikan tersebut dapat di dukung berbagai faktor, 
seperti promosi, pengembangan desa wisata dan pengelolaan desa wisata yang terus di tingkatkan.

Desa Wisata Pulesari secara umum mempunyai potensi utama yaitu wisata alam dan wisata budaya sebagai wisata pendukung. Memanfaatkan potensi alam yaitu aliran sungai dengan membuat wanan air sebagai wisata andalan. Selain itu dengan melestarikan tradisi yang masih dilakukan oleh masyarakat di Pulesari, dapat menjadi obyek wisata pendukung dengan menjual tradisi dan budaya yang ada sebagai paket wisata.

\section{Daya Tarik Wisata}

Desa Wisata Pulesari mempunyai beberapa daya tarik utama dengan mengembangkan potensi alam yang sudah ada di Desa Wisata Pulesari dapat menarik minat wisatawan. Paket wisata outdoor menjadi daya tarik utama di desa wisata Pulesari, susur sungai menjadi wisata andalannya. Kemudian masyarakat di desa wisata Pulesari yang menjadi petani salak juga menjadi daya tarik bagi wisatawan untuk berkunjung sebagai wisata edukasi. Kegiatan masyarakat dalam berkebun salak menjadi wanan edukasi dengan cara menjual paket wisata yang melibatkan antara wisatawan dan petani salak. Wisatawan bisa turun langsung ke area pertanian salak dan di berikan informasi yang barkaiatan dengan tanaman salak. Hasil dari paket wisata kebun salak tersebut diharapkan wisatawan mengetahui tentang budidaya salak pondoh mulai dari menanam, merawat, sampai memanen buah dengan SOP yang benar.

\section{Atraksi seni dan budaya}

Daya tarik pendukung yang ada di Desa Wisata Pulesari yaitu tradisi atau kebiasaan masyarakat. Tradisi masyarakat pada jaman dulu di Pulesari masih dipertahankan sampai sekarang, kegiatan yang masih ada baik yang bersifat religi maupun sosial seperti kenduri, brokohan, tahlilan, gotong- royong, kekompakan warga masyarakat, dan toleransi menjadi minat wisatawan. Dengan 
mempertahankan kearifan lokal dan dijual sebagai paket wisata maka wisatawan akan tertarik. Terdapat dua acara besar yang masih menjadi tradisi sampai saat ini di Pulesari, yaitu acara Sadranan dan upacara Pager Bumi.

Sadranan yang dilakukan setiap bulan ruwah menjelang bulan Ramadhan atau pada tahun 2020 dilaksanakan tangga 17 April 2020. Sadranan merupakan salah satu kegiatan ritual yang dilakukan dengan mendoakan ahli waris dengan bacaan Tahlil di halaman makam. Terdapat juga makanan sebagai wujud sodaqoh, dan berbagai jenis snack. Upacara Pagar Bumi dilakukan pada saat bulan "Sapar Rabu Pungkasan" atau hari Rabu terakhir di bulan Sapar dengan tujuan untuk memperingati khoul Nyai Pulesari dan Kyai Ahmad Nurrohman.

Terdapat beberapa kegiatan yang dilakukan dalam upacara Pagar Bumi. Kegiatan dalam melaksanakan upacara Pagar Bumi yang pertama dilakukan dengan menjalankan beberapa ritual yang menjadi kepercayaan masyarakat Pulesari. Kedua pada hari Rabu sore dilakukan pengambilan air suci yang berasal dari Pajupati Panker yang akan di guyurkan dengan keliling kampung tanpa putus di akhir acara upacara Pagar Bumi. Ketiga adalah pada Rabu malam masyarakat Pulesari melakukan sholat tolak balak, doa bersama, dan mujahadah. Selain itu di lakukan ritual berupa azan sebanyak 41 kali di empat penjuru pancer yang ada di pendopo utama. Terdapat juga berdaga dan tapa bisu dalam uparaca Pagar Bumi, tapa bisu akan keliling kampung dengan membacakan doa, mujahadah, dan tahlil. Selanjutnya tapa bisu akan mengucurkan air suci yang sudah di ambil dari pajupati panker dengan berkeliling kampung tanpa putus.

Pada pelaksanaan upacara pagar bumi juga di meriahkan dengan acara kirab. Terdapat beberapa tumpeng yang dibuat oleh warga seperti, tumpeng ketupat, tumpeng ambegan, dan tumpeng wulu wetu. Pelaksanaan kirab dimulai dari Masjid Darussalam atau masjid utama di Desa Wisata Pulesari menuju makam Pulesari dengan jarak 1,5 meter. Setelah pelaksanaan kirab selesai tumpeng tersebut akan di bagikan kepada masyarakat sekitar dan wisatawan yang hadir. 
Desa Wisata Pulesari juga mempunyai potensi seni budaya lainya berupa pertunjukan kerakyatan yang ditampung dalam sangar dengan nama sanggar Dewi Pule. Kesenian tersebut merupakan bentuk ekspresi dari masyarakat di Pulesari dalam menggambarkan kondisi di lingkungan mereka. Beberapa seni tersebut yaiitu:

- Seni Tari Salak Pondoh Lereng Merapi

Tarian yang ada di Pulesari merupakan sebuah tarian garapan yang sengaja di buat agar menjadi identitas Desa Wisata Pulesari, tarian tersebut bernama tarian Salak Pondoh Lereng Merapi. Tarian ini menggunakan beberapa properti yang berasal dari tanaman salak seperti daun, dan batangnya. Tarian tersebut dimainkan oleh 4 (empat) penari laki- laki yang dilengkapi dengan atribut tandu sebagai tempat salak, kemudian 2 (dua) laki- laki yang berperan sebagai burung berkicau yang ada pada tanaman salak pondoh, serta 8 (delapan) perempuan sebagai penari latar yang bertujuan untuk daya tarik dalam atraksi pementasan.

- Kubro Siswo

Kubro siswo adalah seni ekspresi diri yang mempertunjukkan gerakan dan hampir sama dengan gerakan pencasilat atau bela diri. Tarian kubro siswo berasal dari beberapa mahasiswa yang melakukan Kuliah Kerja Nyata, mahasiswa tersebut kemudian menampilkan tarian Kubro Siswo di hadapan masyarakat Dusun Pulesari pada pentas 17 Agustus tahun 2002.

Nuansa religi yang ada di tarian Kubro Siswo berasal dari cerita yang diambil dari kisah Nabi Muhammad SAW. Pada jaman Nabi Muhammad SAW dengan beberapa pemuda sebagai pengawal Nabi dan para sahabatnya. Mereka ikut berjuang dalam menegakkan ajaran Islam. Sehingga para penari Kubro Siswo menggambarkan pemuda sebagai pengawal Nabi Muhammad SAW yang berjuang menegakkan ajaran Islam dengan adegan peperangan. 
- Kuda Lumping

Kuda lumping atau di daerah Kabupaten Sleman sering di sebut sebagai jathilan, saat ini merupakan pertunjukan kerakyatan yang persebaranannya hampir ada di seluruh wilayah Yogyakarta. Daerah asal kuda lumping yang di kutip dari kemdikbud.go.id yaitu "kuda lumping merupakan cabang kesenian yang berasal dari daerah- daerah di jawa tengah, seperti Magelang, Semarang, Kendal, Pekalongan, Batang, Tegal, Pemalang, Wonosobo, dan Temanggung". Setiap daerah mempunyai ciri khasnya masing- masing. Makna dari pertunjukan kuda lumping adalah sebuah tarian yang menggambarkan tentang semangat perajurit berkuda dalam medan peperangan. Keberadaan kuda lumping di sanggar Dewi Pule merupakan usaha untuk melestarikan pentas kerakyatan tersebut sekaligus sebagai pertunjukan yang di tampilkan di acara- acara tertentu.

- Bergada

Bergada atau bergodo atau dalam istilah bahasa Indonesia adalah prajurit yang ada di Pulesari adalah sebuah simbol pagar di dalam benteng pertahanan. Pada jaman kerajaan bregada merupakan orang- orang yang bertanggung jawab atas keselamatan raja dan benteng pertahanan keraton. Saat ini bergada berusaha di lestarikan untuk dijadikan daya tarik di Desa Wisata Pulesari dengan melibatkannya di setiap acaraacara besar.

- Pewayangan

Pengelolaan kebudayaan yang ada di sanggar Dewi Pule juga menampung tentang "pethilan pewayangan". Pewayangan yang di tampilkan di Pulesari merupakan beberapa cerita yang di ringkas dan menjadi pertunjukan yang digunakan untuk menyambut wisatawan. Namun penampilan pewayangan yang ada di Desa Wisata Pulesari hanya tergantung pada permintaan wisatawan yang datang, jika membutuhkan sambutan makan pewayangan akan tampil, begitu juga sebaliknya. 
- Gobyok Sari dan Klenting Sari

Kesenian gobyok sari dan klenting sari merupakan kesenian religi yang pertunjukannya hampir sama dengan hadroh. Letak perbedaannya yaitu, jika pada hadroh adalah pertunjukan sholawat yang di iringi tabuhan rebana. Sedangkan untuk klenting sari merupakan sholawat berjanji dengan intonasi bahasa jawa atau sholawat jawa atau bisa juga di sebut sebagai unyon- unyon jawa. Sedangkan pada gobyok sari yaitu lebih mengarah pada pitutur jawa yang kemudian dinyanyikan dengan bahasa jawa.

\section{Sarana dan Prasarana}

Terdapat Tempat Ibadah

Fasilitas tempat ibadah bagi umat muslim menjadi hal penting yang harus ada dalam membangun desa wisata halal, karena kewajiban menjalakan sholat 5 (lima) waktu yang tidak bisa di tinggalkan. Desa wisata pulesari menyediakan tempat ibadah dengan 1 Masjid dan 1 Mushola kampung, terdapat juga beberapa mushola yang ada 6 pendopo. Mushola tersebut berada di pendopo utama, pendopo dua, pendopo tiga, pendopo empat, pendopo lima, dan pendopo tujuh. Fasilitas toilet dan tempat wudhu yang berada di Masjid dan pendopo utama terpisah antara laki- laki dan perempuan. Kebersihan di kamar mandi yang ada di Masjid utama cukup baik, namun untuk kamar mandi yang ada di pendopo utama terdapat beberapa kotoran berupa tanah, pasir dan daun- daunan kering yang jatuh dan masuk di ruangan kamar mandi.

\section{Fasilitas Akomodasi}

Fasilitas akomodasi atau tempat tinggal sementara bagi wisatawan termasuk fasilitas pendukung yang di sediakan di desa wisata. Desa Wisata Pulesari termasuk desa wisata yang harus menyediakan fasilitas akomodasi, karena mereka menjual paket wisata dengan kegiatan sehari- hari masyarakat Pulesari. Jumlah total tempat penginapan yang ada di Desa Wisata Pulesari yaitu 59 Homestay. Fasilitas yang harus 
terpenuhi di setiap home stay juga sangat sederhana, minimal yang harus ada di setiap home stay yaitu, kasur, bantal, dan kamar mandi atau toilet. Fasilitas Pariwisata Kabupaten Sleman.

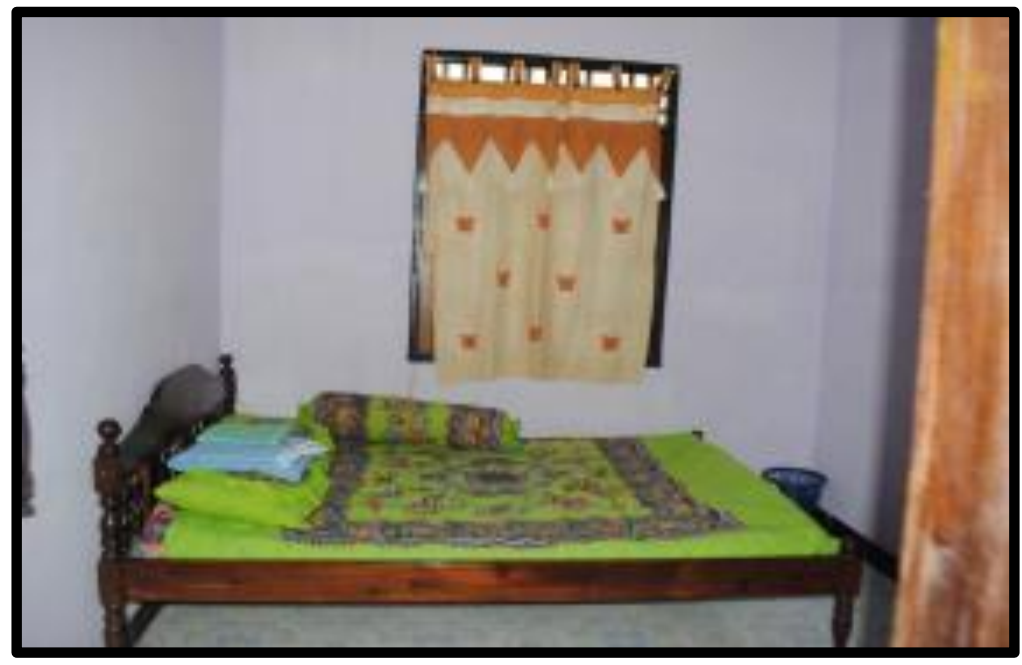

Gambar 2. Home Stay Desa Wisata Pulesari

Sumber: Dokumentasi peneliti

Penyediaan home stay di desa wisata Pulesari berasal dari rumah penduduk yang mempunyai kamar lebih dan bersedia untuk di sewa wisatawan. Paket wisata yang ditawarkan jika wisatawan menggunakan home stay yaitu dengan mengikuti beberapa kegiatan induk semang atau pemilik home stay tersebut. kegiatan sehari- hari seperti memasak sampai berkebun dan bertani menjadi paket wisata di Desa Wisata Pulesari. Wisatawan yang ingin menginap tidak bisa memilih sendiri home stay yang di gunakan, sesuai dengan ketentuan yang ada di Desa Wisata Pulesari. Tujuannya yaitu untuk pemerataan, sehingga jumlah 59 home stay yang ada di Pulesari tidak ada yang lebih ramai atau lebih sepi agar tidak menimbulkan kecemburuan sosial.

\section{Rumah Makan}

Fasilitas rumah makan, warung, atau tempat menjual makanan di desa wisata harus tersedia, tujuannya adalah untuk memenuhi kebutuhan pangan wisatawan selama berwisata di desa wisata. Dalam membangun desa wisata halal kriteria yang harus di penuhi salah satunya makanan yang tersaji harus bersertifikasi halal. Saat ini 
pemenuhan makanan dengan jaminan halal belum sepenuhnya ada di Desa Wisata Pulesari, salah satu alasannya yaitu belum ada regulasi yang mengatur tentang desa wisata halal yang ada di Kabupaten Sleman.

Namun pada pertengah tahun 2019 bekerja sama dengan Universitas Negeri Sunan Kalijaga (UIN) melalui kegiatan Kuliah Kerja Nyata (KKN) mereka mengajukan 3 (tiga) produk makanan yang menjadi ciri khas desa wisata Pulesari untuk disertifikasi halal. Makanan khas yang berasal dari buah salak tersebut menjadi ciri khas Desa Wisata Pulesari, produk tersebut yaitu bakpia salak, wingko salak dan madu mongso salak. Dalam pengolahan produk lokal selain bahan dan rasa yang khas juga harus mempunyai kemasan yang menarik, karena menjadi salah satu faktor wisatawan melirik sebuah produk. Jika produk makanan halal tersebut berkualitas bagus namun tidak di imbangin dengan kemasan yang menarik maka tidak menarik wisatawan untuk membelinya (Zaenuri and Sulaksono 2016).

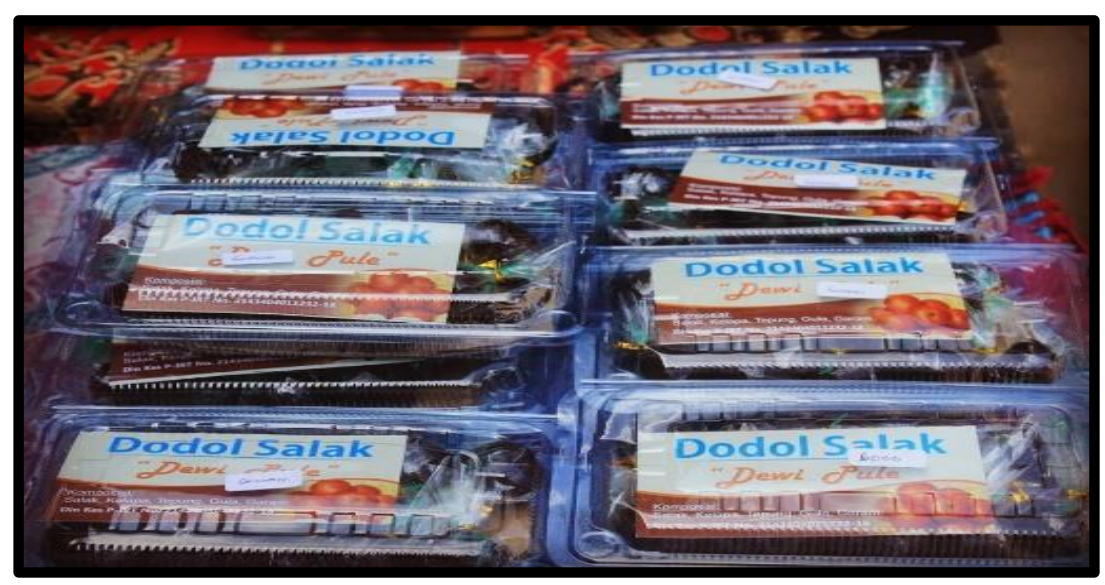

Gambar 3. Produk Dodol Salak

Sumber: Instagram desa wisata Pulesari

Selain 3 (tiga) produk yang bersertifikasi halal, di Desa Wisata Pulesari terdapat produk andalan dan berbagai macam olahan salak. Produk khas yang ada di Pulesari untuk minuman yaitu jaser atau jahe sereh, lalu terdapat kolak salak dan wedang jaburan. Kemudian untuk makanan terdapat oseng- oseng salak dan sambal salak yang menjadi andalannya, terdapat juga menu makanan lainnya seperti sego 
menggono, pepes nila, dan sego pecel. Makanan khas yang berasal dari buah salak menjadi ciri khas desa wisata di Kecamatan Turi salah satunya di Desa Wisata Pulesari.

Pelayanan Bulan Ramadhan

Desa wisata halal berusaha memenuhi kebutuhan wisatawan muslim, termasuk memberikan berbagai macam pelayanan saat bulan suci Ramadhan. Menyediakan menu untuk berbuka dan sahur menjadi pelayanan yang wajib di sediakan, selain itu Masjid/ Mushola yang ada di desa wisata juga melaksakan shalat trawih berjamaah. Usaha untuk tetap melayani wisatawan muslim pada saat bulan ramadhan di Desa Wisata Pulesari tetap dilaksanakan, kebutuhan wisatawan muslim sudah di sediakan oleh pihak desa wisata.

Tidak ada aktifitas non- halal

Aktifitas di desa wisata halal yang ada di Indonesia menurut Kementrian Pariwisata melalui Tim Percepatan Pembangunan Pariwisata Halal salah satunya adalah tidak menyediakan aktifitas Non- Halal. Aktifitas non halal yang di maksud yaitu hiburan malam (diskotik), kegiatan perjudian, dan terdapat minuman beralkohol. Usaha untuk mengolah buah salak yang ada di Pulesari rencananya akan di buat minuman beralkohol (wine) dengan menfermentasi buah salak. Melihat potensi buah salak yang ada di Desa Wisata Pulesari sangat banyak. Namun setelah di kajin oleh pengurus desa wisata akan berdampak negatif, maka pengolahan salak menjadi wine tersebut di batalkan.

Kemudian untuk kegiatan lainya seperti hiburan malam (diskotik) dan kegiatan perjudian juga tidak ada di wilayah Desa Wisata Pulesari. Lingkungan di Desa Wisata Pulesari masih asri, sehingga kondisi pada malam hari sangat sepi dan tidak ada aktifitas- aktifitas yang mengarah pada kegiatan non- halal. 
Pemandu wisata sesuai etika Islam

Pemandu wisata adalah orang yang mempunyai tanggung jawab mendampingi dan memberikan berbagai macam informasi kepada wisatawan terkait desa wisata yang di kunjungi. Dalam melayani wisatawan melalui pemandu wisata Desa Wisata Pulesari mempunyai beberapa peraturan yang harus di penuhi. Desa Wisata Pulesari mempunyai beberapa kriteria untuk menentukan pemandu wisata, terdapat juga tugas- tugas secara umum yang harus di kuasai oleh pemandu wisata. Kriteria dan tugas yang di tetapkan desa wisata Pulesari untuk pemandu wisata yaitu:

- Laki- Laki atau Perempuan dengan usia minimal 18 tahun.

- Untuk perempuan bersedia menggunakan jilbab dan menutup aurat.

- Bersedia untuk melayani dan memberikan informasi untuk wisatawan.

- Ramah dan terbuka kepada wisatawan.

- Menjaga nama baik Desa Wisata Pulesari.

Secara umum seluruh kriteria pemandu wisata sesuai syariat Islam terutama pada poin ke 2 (dua) yang mengatur bagi pemandu wisata perempuan di wajibkan untuk menutup auratnya. Syarat tersebut sejalan dengan yang di tetapkan oleh Kementrian Pariwisata yang mewajibkan bagi pemadu wisata prempuan untuk menutup aurat. Jumlah pemandu di Desa Wisata Pulesari seluruhnya berjumlah sekitar 56 orang yang di dominasi oleh pemuda Karang Taruna Pulesari. Jumlah tersebut terbagi dalam 8 kelompok, 7 kelompok pemandu dan 1 kelompok acara.

\section{Simpulan dan Saran}

Potensi atraksi yang berasal dari tradisi masyarakat yang dapat dikembangkan menjadi desa wisata halal antara lain, kenduri, tahlilan, brokohan, sodaqoh, tradisi upacara sadranan, upacara adat pager bumi, kesenian kubro siswo, kesenian gobyok sari, kesenian klenting sari. 
Beberapa faktor yang berpengaruh dalam pengembangan desa wisata halal di Pulesari antara lain terdapat beberapa kelengkapan fasilitas yang mengutamakan wisatawan muslim seperti tempat wudhu dan toilet yang terpisah antara laki- laki dan perempuan, menyediakan fasilitas berbuka dan sahur saat bulan ramadhan, mempunyai Masjid/ tempat ibadah yang dengan mudah di jangkau wisatawan, melaksakan shalat jumat dan shalat trawih berjamaah bagi wisatawan muslim. Mempunyai produk makanan bersertifikasi halal. Terdapat atraksi yang bernuansa religius seperti upacara adat Pager Bumi, Sadranan, tarian Kubro Siswo, kesenian Gobyok sari, dan kesenian Klentingsari.

Terdapat beberapa Kriteria yang belum terpenuhi dalam mendukung desa wisata halal seperti, makanan halal yang tersaji masih terbatas, kelengkapan fasilitas akomodasi belum siap dan terpenuhi. Fasilitas ibadah masih mempunyai kekurangan, tempat wudhu terpisah masih terbatas yaitu hanya pada Masjid dan pendopo utama, kebersihan mushola masih rendah.

Pemerintah Kabupaten Sleman segera menyusun peraturan tentang pengembangan desa wisata halal agar pengembangan desa wisata halal dapat di lakukan dan memiliki dasar hukum. Desa Wisata Pulesari di perlukan pembangunan fasilitas pendukung lainya yang mengarah pada pelayanan wisatawan muslim. Seperti menyediakan fasilitas tempat wudhu dan toilet terpisah antara laki- laki dan perempuan di semua titik baik pendopo maupun Mushola, menjaga kebersihan tempat ibadah dan toilet, melengkapi fasilitas Al-Quran di setiap home stay, dan meyediakan ruang khusus perempuan di setiap home stay, dan dalam jangka panjang untuk memperbanyak makanan dan minuman yang sudah bersertifikasi halal.

\section{Ucapan Terimakasih}

Penulis pertama dan yang utama mengucapkan terima kasih banyak kepada Tuhan yang Maha Kuasa karena memberikan kemudahan dan kelancaran dalam proses penelitian kami. Kedua kepada orang tua dan dosen pembimbing yang selalu 
sabar dalam memberikan arahan dan masukan. Ucapan terima kasih juga kepada Dinas Pariwisata Kabupaten Sleman dan pengurus desa wisata Pulesari yang telah bersedia memberikat keterangan yang berkaitan dengan penelitian ini. Serta temanteman baik dari lingkungan dan di luar lingkungan Universitas Muhammadiyah Yogyakarta yang sudah memberikan semangat serta dorongan motivasi untuk menyelesaikan penelitian ini dengan tujuan untuk menyelesaikan program pendidikan S1.

\section{Daftar Pustaka}

Bagus, Raden, and Faizal Irany. 2017. “Optimalisasi Peran Perbankan Syariah Dalam Mendukung Wisata Halal." 5(2): 1-14.

Burhan, Fahmi Ahmad. (2018). Desa Wisata Di Sleman Bakal Jadi Desa Wisata Halal. Diakses pada 06 Februari 2020, dari https://wisata.harianjogja.com/read/2019/07/05/504/1003437/desa-di slemanini-bakal-dijadikan-desa-wisata-halal

Destiana, Riska, Retno Sunu Astuti. 2019. "Pengembangan Pariwisata Halal di Indonesia." 01(01): 331-53.

Ermando, Alexander. (2019). Bertambah Signifikan Desa Wisata Di Sleman Kini Berjumlah 47. Diakses pada 06 Februari 2020, dari https://jogja.tribunnews.com/2019/03/13/bertambah-signifikan-desa wisata-disleman-kini-berjumlah-47

Jejen, Tajudin. 2015. “Strategi Pengembangan Desa Wisata di Mangunan dalam Meningkatkan pendapatan asli Desa (PASES) Desa Mangunan, Kecamatan Dlingo, Kabupaten Bantul. Universitas Muhamadiyah Yogyakarta

Juniawandahlan. (2017). Jathilan Jaran Kepang Pertunjukan Rakyat Kuda Lumping Di Jawa Tengah. Diakses pada 13 April 2020, dari https://kebudayaan.kemdikbud.go.id/mkn/jathilanjaran-kepang pertunjukan-rakyat-kuda-lumping-dijawa-tengah/

Marsono. 2019. Agro dan Desa Wisata. Yogyakarta. Gadjah Mada University Press.

Novita, Angghi. (2019). Lombok Sabet Juara Destinasi Pariwisata Halal TerbaikIndonesia. Diakses pada 11 Maret 2020, dari https://www.gatra.com/detail/news/408877Lombok-Sabet-Juara Destinasi-Pariwisata-Halal-Terbaik-Indonesia 
Putra, Dwi Aditya. (2018). Data BPS: Indonesia Memiliki 1.734 Desa Wisata. Diakses pada 06 Februari 2020, dari https://www.merdeka.com/uang/data bpsindonesia-miliki-1734-desa-wisata.html

Rahmasari, Anggraeni, and Juliani Pudjowati. 2017. "Strategi Pengembangan Desa Inovasi Pariwisata Kota Batu Dengan Local Economic Resources Development ( LERD )."

Sedarmayanti, dkk. 2018. Pembangunan Dan Pengembangan Pariwisata. Bandung. Refika.

Subarkah, Alwafi Ridho. 2018. "Potensi Dan Prospek Wisata Halal Dalam Meningkatkan Ekonomi Daerah ( Studi Kasus : Nusa Tenggara Barat )." Jurnal Sospol 4(2): 49-72.

Wardani, Ni Wayan Novi Sukma, and I Gd Astra Wesnawa. 2018. "Potensi Ekowisata Kampoeng Kepiting Di Desa Tuban, Kecamatan Kuta, Kabupaten Badung." Jurnal Pendidikan Geografi Undiksha 6(1): 1-12.

Zaenuri, Muchamad, and Tunjung Sulaksono. 2016. “Pengembangan Pemasaran Makanan Berbahan Baku Ketela Untuk Mendukung Wisata Kuliner Di Yogyakarta." Jurnal Berdikari 04(01): 31-43.

\section{Profil Penulis}

Dr, Muchamad Zaenuri, M.Si. adalah dosen Program Studi Ilmu Pemerintahan, Universitas Muhammadiyah Yogyakarta yang saat ini mempunyai jabatan sebagai Ketua Program Studi Ilmu Pemerintahan UMY dengan periode 2016 samapai 2021. Riwayat pendidikan beliau yaitu lulusan program sarjana dari Universitas Gadjah Mada dengan bidang ilmu yaitu Ilmu Pemerintahan lulus pada tahun 1991. Kemudian program magister dengan bidang ilmu Administrasi Publik di Universitas Gadjah Mada yang lulus pada tahun 2003. Serta program doktor dengan bidang ilmu Administrasi Publik di Universitas Brawijaya yang lulus pada tahun 2017.

Tareq Azis Yanma, adalah seorang mahasiswa Program Studi Ilmu Pemerintahan Fakultas Ilmu Sosial dan Politik Universitas Muhammadiyah Yogyakarta yang mengambil penelitian terkait desa wisata Pulesari menuju desa wisata halal sebagai pemenuhan tugas akhir dan syarat kelulusan sebagai Sarjana Ilmu Pemerintahan. 